\title{
Efficacy of Radiofrequency Ablation versus Percutaneous Ethanol Injection in Treating Small HCC among Cirrhotic/bilharzial Patients
}

\author{
Abdelkader, Abeer Hussein ${ }^{1}$, Abdelmoaty, Ahmed ${ }^{1}$, Elkolly, Mohamed Magdy ${ }^{2}$ \\ ${ }^{I}$ Tropical Medicine Departments, Faculty of Human Medicine, Zagazig University, Egypt \\ ${ }^{2}$ Gastroentrology Department, Zifta General Hospital,Zefta, Gharpiah governorate, Egypt
}

Corresponding Author Abdelkader, Abeer Hussein

Mobile:

01062537899

E mail:

abeeralashry0@gmail. com

Key words: HCC; Percutaneous ethanol injection; Radiofrequency; Bilharziasis.
Background and study aim: The incidence of hepatocellular carcinoma (HCC) is rising worldwide being the fifth most common cancer and the third cause of cancer-related mortality. Early detection of HCC is associated with a better outcome. In Egypt and over the last decades, a remarkable rise of HCC was observed in the proportion of chronic liver disease patients. The aim of this study is to compare between Radiofrequency ablation (RF) \& Percutaneous Ethanol Injection (PEI) in treating small $\mathrm{HCC}$ in cirrhotic /bilharzial patients.

Patients and Methods: We divided patients into two groups; Group 1: $(n=24)$ were HCC patients with small focal lesions treated by ethanol injection therapy using 99\% sterile alcohol delivered in the lesion through a 21-gauge needle, amount of alcohol not exceeding

\section{INTRODUCTION}

Hepatocellular carcinoma (HCC) rank $5^{\text {th }}$ worldwide cancer and rank $3^{\text {rd }}$ cause of cancer mortality with over half a million new cases diagnosed annually worldwide. [1-4]

In Egypt and over the last decades, a rise from $4.0 \%$ to $7.2 \%$ was observed in the proportion of chronic liver disease patients diagnosed with HCC. [5-7]

The curative treatment modalities available for HCC include surgical resection, liver transplantation and percutaneous ablation. [8] Unfortunately, only $20 \%$ of HCC patients are suitable for surgical resection and high recurrence rate is frequent even after this resection. [9]

Image-guided ablation therapies are used in treatment of HCC patients unfit for surgical treatment [10].
$10 \mathrm{ml}$ every session. Group II: $(\mathrm{n}=24)$ were HCC patients with small focal lesions treated by radiofrequency ablation using Leveen Needle Electrode.patients were followed up at 1 and 3 months by abdominal ultrasoungraphy\& triphasic $\mathrm{CT}$ to assess ablation status.

Results: The 2 groups are comparable regarding their baseline. The incidence of HCC ablation by PEI is $87.5 \%$ while it was to $91.7 \%$ in the radiofrequency ablation group with no relapse after 3 months follow up. In both groups, this difference was not statistically significant.

Conclusion: The Efficacy of PEI therapy is not inferior to percutaneous RF ablation in the treatment of small HCC lesions up to $2.5 \mathrm{~cm}$ in patients with mixed cirrhosis/bilharzial hepatic fibrosis.

These therapies are divided into two groups chemical ablation (like ethanol and acetic acid), heat ablation (as radiofrequency, microwave, and laser) [11-16]. Percutaneous ethanol injection therapy (PEIT) a chemical ablation was proposed as the standared treatment for small HCC less than $2 \mathrm{~cm}[\mathbf{1 7 , 1 8}]$ Radiofrequency (RF) was proposed as the most commonly used thermal ablation therapy worldwide and is used for treatment of early stage of HCC [19]. It provide almost similar therapeutic effect in $\mathrm{HCC}<2.0 \mathrm{~cm}$ compared to Percutaneous ethanol injection therapy [20, 21]. However this was not studied in patients with combined liver cirrhosis \& bilharzial hepatic fibrosis. 
This Study aimed to compare the therapeutic efficacy of PEI versus RF in hepatocellular carcinoma less than $2.5 \mathrm{~cm}$ among Egyptian patients with combined cirrhosis /bilharzial hepatic fibrosis.

\section{PATIENTS AND METHODS}

This prospective cohort study was conducted in Tropical Medicine Department, Zagazig University Hospitals, Egypt during the period between November 2017 and July 2018. A total of 48 naive HCC patients were included in this study.

\section{Inclusion criteria:}

Patients of age above 18 years, any sex, those with combined liver cirrhosis/bilharzial hepatic fibrosis were included with the following criteria.

1) One $\mathrm{HCC}$ lesion of $\leq 2.5 \mathrm{~cm}$ in diameter.

2) All focal lesions away from important structures with no evidence of vascular invasion or extrahepatic spread.

3) Child-Pugh class A or B.

4) Platelet count more than 70,000 cells/dl.

5) No ascites refractory to diuretics.

6) Bilirubin not more than $3 \mathrm{mg}$, INR not more than 1.5.

7) Patients with $\mathrm{HCC}$ in close proximity to biliary tracts, stomach, colon, gall bladder or big blood vessels were preferably treated by PEI.

\section{Exclusion criteria:}

1) Patients refused to be enrolled.

2) Patients with previous intervention
maneuvers.

3) Patients not fulfilling the inclusion criteria

\section{Patients were divided into two groups:}

Group I $(n=24)$ HCC patients with small focal lesion $\leq 2.5 \mathrm{~cm}$ treated by PEI

Group II $(n=24)$ HCC patient with small focal lesion $\leq 2.5 \mathrm{~cm}$ treated by RF.

\section{Methods:}

Pretreatment assessment: all patients were subjected to:

- Full history taking and Thorough clinical examination
- Laboratory investigations: Complete blood picture (CBC), liver biochemistry (S. bilirubin, SGOT, SGPT, total protein and S. albumin), coagulation profile (PT, INR), kidney function (S. creatinine) Alpha-feto protein $(\alpha-F P)$.

- Abdominal ultrasound with color doppler for detection of liver cirrhosis, bilharzial hepatic fibrosis, liver focal lesion (site, number, size, vascular invasion), portal vein diameter and thrombosis inside, spleen size, presence of ascites, and other intraabdominal masses or collections.

US criteria for diagnosis of liver cirrhosis: altered parenchymal echogenicity with coarse echotexture and surface nodularity and hypoechoic nodules which represent regenerative nodules and fibrous septa. [22]

US criteria for diagnosis of bilharzial hepatic fibrosis: septal fibrosis, portal wall thickening and increased echogenicity, mosaic pattern: echogenic septa in areas of relatively normal liver parenchyma, splenomegaly. [22-26]

\section{- Triphasic CT:}

Performed for all patients in both groups and was considered the gold standard for diagnosis of HCC.

Triphasic C.T. is composed mainly of three phases and malignant lesions appear enhanced in the arterial phase followed by rapid washout in the porto-venous. [27]

\section{A. Treatment:}

All patients were fasting for at least 6 hours before the procedure.

Both procedures (PEI\& RFA) were performed under US guidance. The procedures were performed in operating room in the presence of an anesthesiologist with injection of $1 \%$ lidocaine starting from the skin down to the lesion. The aim of the treatments was to destrcut the total tumor with a safe border of $0.5-1.0 \mathrm{~cm}$.

\section{Precutaneous RF ablation:}

It was done by using Leveen Needle Electrode; Radiotherapeutics. It has curved electrodes and an insulated 17-gauge outer needle that houses 10 solid retractable curved electrodes that, when enter the lesion, assume the configuration of an umbrella. The alternating electric current generator is $200 \mathrm{~W}$ operated at $480 \mathrm{kHz}(\mathrm{RF}$ 
3000; Boston Scientific). After the RF procedure was finished the electrodes were removed and the track was cauterized along its length up to just below the liver capsule to prevent bleeding or possible tumor spread.

\section{Precutaneous ethanol injection (PEI):}

PEI administered to each patient (1-3 sessions weekly) using $99.5 \%$ sterile ethanol with a 21 gauge needle (Et-hanoject, TSK, Tokyo, Japan) having multiple-side-hole. [28, 29] Amount of alcohol calculated according to the following equation: $V=3 / 4 \pi(r+0.5) 3$

Where $\mathbf{V}$ is the total volume of alcohol in milliliter (ml) and $\mathbf{r}$ is the radius of the tumor in centimeters and $0.5 \mathrm{~cm}$ is added as a safety margin. Amount of alcohol not exceeding $10 \mathrm{ml}$ per session

US scan during the injection allowed the evaluation of the alcohol spread which appear as intense hyperechogenicity of the lesion. [30]

Follow up: All patients of both groups were followed up one month and three months after completing ablations as follows:

Abdominal US was done to detect changes in the ablated lesion (size and echogencity), detect reappearance of intra-lesional arterial signals (indicating recurrence), appearance of new lesions, abdominal lymph nodes or ascites and portal vein thrombosis.

Good ablation appear when the tumor become echogenic, no arterial signal and the size decrease or remained the same

Triphasic CT was done after ablation to demonstrate reappearance of arterial enhancement in the ablated lesions (recurrence), De Novo focal lesions and PV thrombosis. [31]

The efficacy of both PEI and RFA was evaluated in all cases with enhanced CT one and three months after the procedure and necrosis was defined as complete when the lesion appeared none enhanced in the arterial phase.

\section{Statistical Analysis}

The collected data were computerized and statistically analyzed using SPSS program (Statistical Package for Social Science) version 20.0. Quantitative data were expressed as mean \pm SD Continuous data were checked for normality by using Shapiro Walk test. T-test was used to compare between two groups of normally distributed variables while Mann Whitney U test was used for non- normally distributed variables. Fisher's exact test when appropriate. Significance was defined as $\mathrm{P}<0.05[32]$.

\section{RESULTS}

Patients in this study were collected from different hospitals in the area due to strict inclusion criteria were applied. From 433 HCC patients examined during the study period, A total of 48 patients with small HCC less than 2.5 $\mathrm{cm}$ in diameter were included for therapeutic intervention,

32 males and 16 females, age range from 43 to 80 years (Table 1). There were

All patients were treated in HCC unit of the tropical Medicine Department, Zagazig university hospitals, Zagazig, Egypt.

The most common site of tumor location were in the right lobe: segment 6 (14 patients, 29\%), segment 7 (12 patients, 25\%), segment 5 (11 patients, 22.9\%) and left lobe: segment $3(8$ patients, $16.6 \%$ ). The least incidence was in caudate lobe and segment 6 subcapsular location (one patient in each). (Table 2)

The baseline demographic and laboratory data were not stastitically different between both groups (Table 3).

The primary outcome of this study was the rate of HCC ablation at 1 and 3 months. At one month RF ablation was little bite effective than PET (91.7\% vs $87.5 \%$ respectively ) although the difference was not statistically significant $(\mathrm{p}$ : 0.99).

At 3 months all patients in both groups maintained these ablation state and were equally effective at 3 month post ablation (Table 4).

In both groups there was no mortality at 3 month. Furthmore, no severe adverse events were reported during intervention and at 3 months follow up period. All the reported side effects were mild including minor bleeding at injection site, pain, fever, vomiting and feeling heaviness at intervention site. The thermal ablation of right lobe focal lesion by RF was associated with pleural effusion in one patient while PEI of subcapsular lesion was associated with appearance of mild ascites in another patient although the difference was not stastitically significant (Table 5). 
Table 1: Demographic data of the studied groups.

\begin{tabular}{|l|c|c|c|}
\hline \multirow{2}{*}{ items } & \multicolumn{2}{|c|}{ Studied groups } & \multirow{2}{*}{ P value } \\
\cline { 2 - 3 } & Group1 (n=24) & Group II (n=24) & \\
Age (years) & & & \multirow{2}{*}{0.43} \\
(Mean \pm SD ) & $60 \pm 7$ & $58 \pm 9.2$ & \\
Median (range) & $46-75$ & $43-80$ & - \\
\hline Gender (M/F) & $16 / 8(2)$ & $16 / 8(2)$ & \\
\hline Child score A/B & $20 / 4$ & $19 / 5$ & \\
\hline
\end{tabular}

Table 2: Site of lesion of both groups.

\begin{tabular}{|l|c|c|c|}
\hline \multirow{2}{*}{} & \multicolumn{2}{|c|}{ Studied groups } & \multirow{2}{*}{ Total } \\
\cline { 2 - 3 } & $\begin{array}{c}\text { Group I (n=24) } \\
\text { N (\%) }\end{array}$ & $\begin{array}{c}\text { Group II (n=24) } \\
\text { N (\%) }\end{array}$ & \\
\hline Caudate & $1(4.2)$ & 0 & 1 \\
\hline Segment 3 & $2(8.3)$ & $6(25)$ & 11 \\
\hline Segment 5 & $4(16.7)$ & $7(29.1)$ & 14 \\
\hline segment 6 & $7(29.1)$ & $7(29.1)$ & 12 \\
\hline segment 7 & $9(37.5)$ & $3(12.5)$ & 1 \\
\hline segment 8 & 0 & $1(4.2)$ & 1 \\
\hline Subcapsular /s6 & $1(4.2)$ & 0 & \\
\hline
\end{tabular}

Table 3: Laboratory finding of both groups.

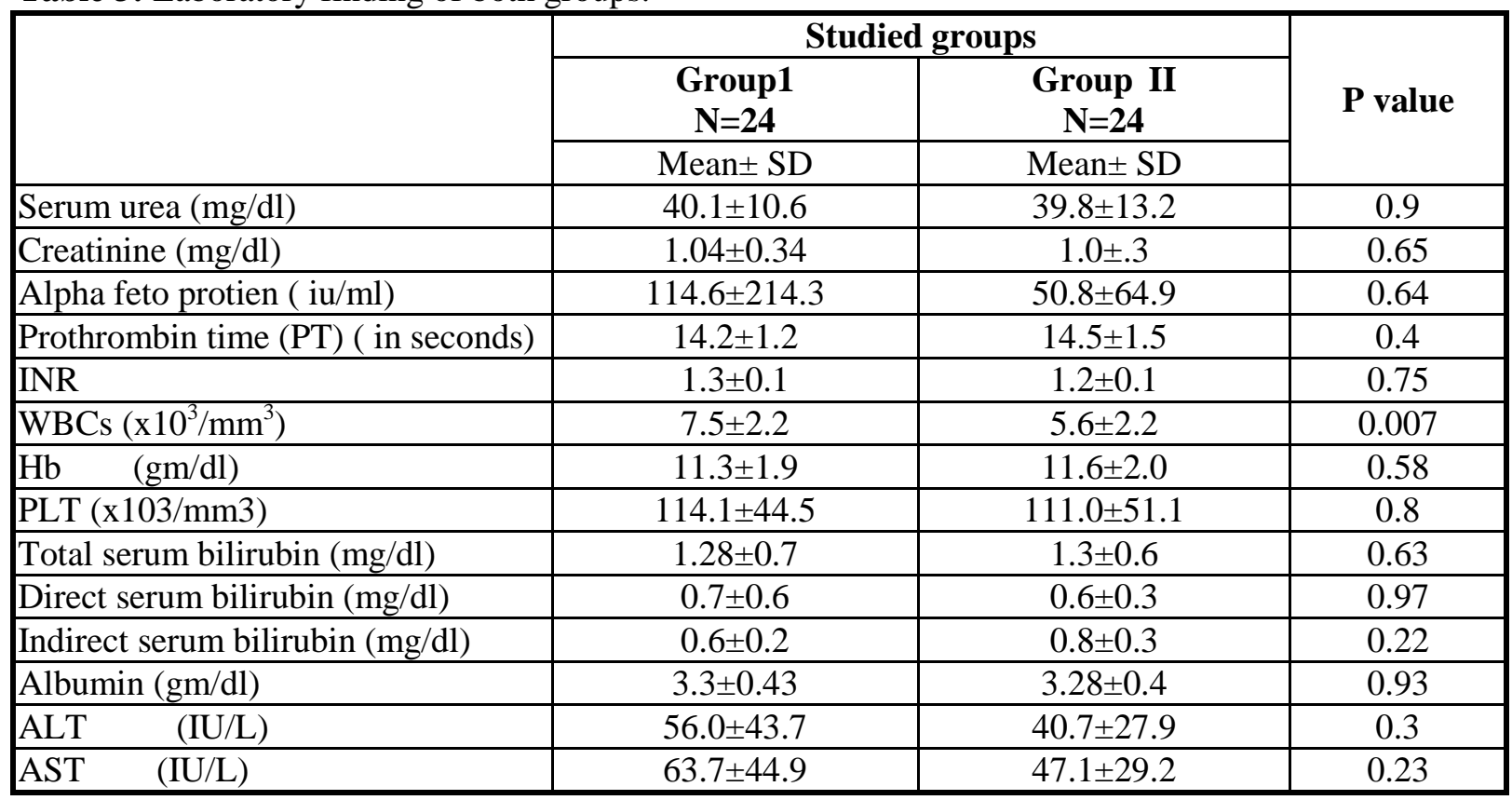

Table 4: Outcome of ablation after one and three month follow up.

\begin{tabular}{|l|c|c|c|}
\hline \multirow{2}{*}{ Outcome after one month } & \multicolumn{2}{|c|}{ Studied groups } & \multirow{2}{*}{$*$} \\
\cline { 2 - 3 } & $\begin{array}{c}\text { Group I (n=24) } \\
\mathbf{N}(\boldsymbol{\%})\end{array}$ & $\begin{array}{c}\text { Group II (n=24) } \\
\mathbf{N}(\boldsymbol{\%})\end{array}$ & \\
\hline A ablated & $21(87.5)$ & $22(91.7)$ & \multirow{2}{*}{0.99} \\
\hline Not ablated & $3(12.5)$ & $2(8.3)$ & 0.99 \\
\hline Outcome after three month & $21(100)$ & $22(100)$ & \\
\hline A ablated & \multicolumn{2}{|c|}{} \\
\hline
\end{tabular}


Table 5: Complications in both groups.

\begin{tabular}{|c|c|c|c|c|}
\hline \multicolumn{2}{|c|}{ Complications } & Group I & Group II & $\mathbf{P}$ \\
\hline \multirow[t]{2}{*}{ Pain } & present & $17(70.8)$ & $20(83.3)$ & \multirow{2}{*}{0.3} \\
\hline & absent & $7(29.2)$ & $4(16.7)$ & \\
\hline \multirow[t]{2}{*}{ Fever } & present & $6(25)$ & $8(33.3)$ & \multirow{2}{*}{0.52} \\
\hline & absent & $18(75)$ & $16(66.7)$ & \\
\hline \multirow{2}{*}{ Vomiting } & present & $2(8.3)$ & $1(4.1)$ & \multirow{2}{*}{0.99} \\
\hline & absent & $22(91.7)$ & $23(95.9)$ & \\
\hline \multirow[t]{2}{*}{ Pleural effusion } & present & 0 & $1(4.1)$ & \multirow{2}{*}{0.99} \\
\hline & absent & $24(100)$ & $23(95.9)$ & \\
\hline \multirow[t]{2}{*}{ Ascites } & present & $1(4.1)$ & 0 & \multirow{2}{*}{0.99} \\
\hline & absent & $23(95.9)$ & $24(100)$ & \\
\hline \multirow[t]{2}{*}{ Total } & $\mathrm{N}$ & 24 & 24 & \\
\hline & $\%$ & $100.0 \%$ & $100.0 \%$ & \\
\hline
\end{tabular}

\section{DISCUSSION}

There is a remarkable rise in the rate of HCC among Egyptian adults with chronic liver diseases. Egypt known to have the highest prevalence of $\mathrm{HCV}$ worldwide and this increased the rate of liver cirrhosis and HCC. Also Bilharziasis is endemic in Egypt since the age of the Pharaohs.

Deposition of bilharezial hepatic fibrosis is expected to add technical challenge to HCC ablation because in our Egyptian community it's not uncommon to see pateients with combined cirrhosis /hepatic fibrosis having small HCC and it's not clear in this subgroup of patients which intervention is superior and hence we planned for this study.

In our study, $\mathrm{HCC}$ most commonly presented in males (32 males, 67\%) more than females (16 females, $33 \%$ ), with ratio $2: 1$.This result is similar to that reported in Egyptian literature by Abdelaziz, et al. [33] who found that $71 \%$ of the studied patients with HCC were males and $29 \%$ were females. This result is similar to that reported by El-Zyadi, et al. [34] who found that $77.7 \%$ of the studied patients with HCC were males and $22.3 \%$ of patients were females, with a calculated risk of development of HCC that was nearly three times higher in men than in women. This is consistent also with international literature where $\mathrm{Lu}$ et al., [35], found that $85 \%$ of their studied patients, were males and $15 \%$ were females. Till now, there are no satisfactory explanations for this phenomenon, which may be at least in part explained by differences in exposure to risk factors.
We know that the only definitive curative treatment for $\mathrm{HCC}$ is liver resection and liver transplantation. However in the Egyptian community both options are not widely practiced. First, due to late presentation of many cases and poor functional status in others. Second due to shortage in donors, technical difficulties and financial issues. Consequently, only $10-20 \%$ of all patients are potential candidates for both treatments.

Hence most of the patients are directed to locoregional therapies. Among modalities available RF \& PEI are widely practiced. Because of their efficacy, simplicity, affordable cost and accepted adverse events especially in the small lesion and that why they were used in the current study.

In the current study both RF \&PEI were found effective in ablating small HCC less than $2.5 \mathrm{~cm}$ in cirrhotic/bilharzial patients.

It is known that fibrotic tissue is tough to penetration and it was expected that presence of bilharzial hepatic fibrosis beside cirrhosis will add technical difficulties to locoreginal treatment in this study. However both PEI \& RF needles were directed correctly to the lesion and its site was precisely determined by US.

We didn't begin intervention except after assessing correct position, manipulation of the needles was somewhat difficult due to fibrosis, yet correct position was achieved in all patients.

The efficacy of each therapeutic modality in ablating small HCC was confirmed. RF was tried in many studies $[19,36-39]$ to achieve ablation rate $83-96 \%$ with accepted rate of complication. 
PEI was also described in the guidelines as effective as RF in treating small lesion especially when the lesion is close to liver surface, vascular, or biliary tract.

However RF is a single session (most of the time) procedure, while PEI had to done in multiple sessions.

To the best of our Knowledge this is the first study to target cirrhotic/bilharzial patients with small HCC comparing RF\& PEI due to limited percentage of bilharzial hepatic fibrosis in certain communities.

Our results showed similarity between RF and PEI in management of small HCC which is in agreement with Giorgio et al who randomly assigned patients with a single $\mathrm{HCC} \leq 3 \mathrm{~cm}$ to receive PEI or RFA, with similar efficacy and comparable 3-year survival rate [36]

When both treatments are viewed from the complication side it will be obvious that most of the reported side effects are mild and range from pain, vomiting, fever. However thermal ablation with RF affects the pleura and developed pleural effusion while chemical injection of the liver capsule in PEI gave a mild ascites in one patients althought the difference was not statistically significant.

This study had some limitations. First, the small number of patients and this is directly related to the sharp inclusion criteria were applied. Our aim was to treate combined cirrhotic/ bilharzial patients with small HCC. Second, nonrandomized nature of the study and this is due to the cost which patients can afforde. Third. Lack of long term follow up to check the rate of recurrance and determine the survival. In Egypt we don't have data base for our patients and hence great proportion of our patients are lost in long term follow up.

In conclusion: The Efficacy of percutaneous ethanol injection therapy is almost similar to percutaneous radiofrequency ablation in treatment of small HCC lesions up to $2.5 \mathrm{~cm}$ in cirrhotic / bilharzial with accepted complication rate and no added technical problems.

Ethical consideration: Ethical approval was obtained from the Committee of Research, Publications and Ethics of the college of Medicine, Zagazig University, Egypt. All procedures were explained to patients and a written or thumb-printed informed consent was obtained.
Conflict of Interest: none.

Funding: none.

\section{REFERENCES}

1. Ferly J, Shin HR and Bray F, Forman D, Mathers C, Parkin DM. Estimates of world-wide burden of cancer in 2008: GLOBOCAN 2008. International journal of cancer 2010; 127(12): 2893-917.

2. McGlynn KA, London WT. The global epidemiology of hepatocellular carcinoma: present and future. Clin Liver Dis. 2011 May;15(2):223-43.

3. Mittal S and El-Serag .HB Epidemiology of HCC: Consider the population. $J$ Clin Gastroenterol. 2013; 47(0): S2-S6.

4. Ozakyol A . Global Epidemiology of Hepatocellular Carcinoma (HCC Epidemiology). J Gastrointest Cancer 2017; 48:238-240.

5. Abdel-Hamid NM, Nazmy MH, Mahmoud AW, Fawzy MA, Youssof M. A survey on herbal management of hepatocellular carcinoma. World J Hepatol. 2011; 3(7):175-83.

6. Freedman LS, Edwards BK, Ries LAG. Cancer incidence in four member countries (Cyprus, Egypt, Israel, and Jordan) of the Middle East cancer consortium (MECC) compared with US SEER. Bethesda: National Cancer Institute; 2006

7. National Cancer Registry of Egypt. Magnitude of hepatocellular carcinoma in Egypt. 2010. Available from: http://www.nci.cu.edu.eg/.

8. Bruix J, Sherman M, Llovet JM, Beaugrand M, Lencioni R, Burroughs AK, et al. Clinical management of hepatocellular carcinoma. Conclusions of the barcelona-2000 EASL conference. J Hepatol 2001; 35:421-430.

9. Borie F, Bouvier AM, Herrero A, Faivre J, Launoy G, Delafosse P, et al. Treatment and prognosis of hepatocellular carcinoma: A population based study in France. J Surg Oncol. 2008; 98:505-509.

10. Goldberg SN and Ahmed M. Minimally invasive image-guided therapies for hepatocellular carcinoma. J Clin Gastroenterology. 2002; 35:S115-129.

11. Livraghi T., Festi D., Monti F., Salmi A., and Vettori C., "US guided percutaneous alcohol injection of small hepatic and abdominal tumors, " Radiology. 1986, vol. 161, no. 2, pp. 309-312. 
12. Shiina S., Yasuda H., Muto H. Tagawa K, Unuma T, Ibukuro K.et al., Percutaneous ethanol injection in the treatment of liver neoplasms. AJR. American journal of roentgenology. 1987 Nov; 149(5):949-52.

13. Seki T., Wakabayashi M., Nakagawa T. Seki T, Wakabayashi M, Nakagawa $T$, et al. Ultrasonically guided percutaneous microwave coagulation therapy for small hepatocellular carcinoma. Cancer.1994 Aug 1; 74(3):817-25.

14. S. Rossi , Di Stasi M, Buscarini E, Cavanna L, Quaretti P, Squassante E, et al. Percutaneous radiofrequency interstitial thermal ablation in the treatment of small hepatocellular carcinoma. Cancer J Sci Am. 1995 May-Jun; 1(1):73-81.

15. Livraghi T, Goldberg SN, Lazzaroni S, Meloni F, Solbiati L, Gazelle GS. . Small hepatocellular carcinoma: treatment with radio-frequency ablation versus ethanol injection. Radiology. 1999 Mar; 210(3):655-61.

16. Shiina S,. Teratani T., Obi S. Sato S, Tateishi $\mathrm{R}$, Fujishima T, et al. A randomized controlled trial of radiofrequency ablation with ethanol injection for small hepatocellular carcinoma. Gastroenterology. 2005 Jul;129(1):122-30.

17. Livraghi T, Giorgio A and Marin G, Salmi A, de Sio I, Bolondi L,et al. Hepatocellular carcinoma and cirrhosis in 746 patients: long-term results of percutaneous ethanol injection. Radiology.1995; 197: 101-108.

18. Bruix $\mathbf{J}$ and Sherman M. American Association for the Study of Liver D. Management of hepatocellular carcinoma: an update. Hepatology. 2011; 53:1020-22.

19. Qian GJ, Wang N and Shen Q, Sheng YH, Zhao JQ, Kuang M, et al. Efficacy of microwave versus radiofrequency ablation for treatment of small hepatocellular carcinoma: experimental and clinical studies. Eur Radiol 2012, 22: 198390.

20. Giorgio A Percutaneous ethanol injection in the treatment of hepatocellular carcinoma in cirrhosis: a simple, effective and cheap procedure for percutaneous ablation. $J$ Gastrointestin Liver Dis. 2010; 19: 461-7.

21. Signoriello S, Annunziata A, Lama N, Signoriello G, Chiodini P, De Sio I, et al. Survival after locoregional treatments for hepatocellular carcinoma: a cohort study in realworld patients. Scientific World Journal. 2012:564706.

22. Heller MT, Tublin ME. The role of ultrasonography in the evaluation of diffuse liver disease. Radiol Clin North Am. 2014; 52:11631175.
23. Hussain S., Hawass N.D. , Zaidi A.J. Ultrasonographic diagnosis of schistosomal periportal fibrosis. Journal of ultrasound in medicine official J Am Inst Ultrasound Med, (1984), 3 (10) pp. 449-452.

24. Fataar S., Bassiony H. , Satyanath S. , Vassileva J. , Hanna R.M. Characteristic sonographic features of schistosomal periportal fibrosis . Am J Roentgenol; (1984), 143 (1) pp. 69-71.

25. Cerri G.G., Alves V.A., Magalhaes A. . Hepatosplenic schistosomiasis mansoni: ultrasound manifestations. Radiology, (1984), 153 (3) pp. 777-780.

26. Strickland G.T., Abdel-Wahab M.F. Abdominal ultrasonography for assessing morbidity from schistosomiasis. Community studies. Trans $R$ Soc Trop Med Hyg. 1993 Mar-Apr; 87(2):132134.

27. Colli A, Fraquelli M, Casazza G, Massironi S, Colucci A, Conte D. et al. Accuracy of ultrasonography, spiral CT, magnetic resonance, and alpha-fetoprotein in diagnosing hepatocellular carcinoma: a systematic review. Am J Gastroenterol. 2006; 101:513-523.

28. Kang HW, Kim YJ, Kim KM, Kang JM, Kim $\mathrm{SH}$, Kim JH et al . [Efficacy of percutaneous ethanol injection therapy in Korean with hepatocellular carcinoma]. Korean $J$ Gastroenterol 2003; 42:502-9.

29. Bartolozzi C and Lencioni R. Ethanol injection for the treatment of hepatic tumors. Eur Radiol. 1996; 6:682-96.

30. Giorgio A, Tarantino L, de Stefano G, Perrotta A, Aloisio V, del Viscovo L, et al. Ultrasoundguided percutaneous ethanol injection under general anesthesia for the treatment of hepatocellular carcinoma on cirrhosis: long-term results in 268 patients. Eur J Ultrasound. 2000 Dec; 12(2):145-54.

31. Iannaccone R, Laghi A, Catalano C, Rossi P, Mangiapane F, Murakami T, et al. Hepatocellular carcinoma: role of unenhanced and delayed phase multi-detector row helical CT in patients with cirrhosis. Radiology. 2005; 234:460-467.

32. Elliott AC \& Woodward WA, Statistical analysis quick reference guidebook: With SPSS examples 2007.

33. Abdelaziz A, Elbaz $\mathrm{T}$ and Shousha HI, et al. Efficacy and survival analysis of percutaneous radiofrequency versus microwave ablation for hepatocellular carcinoma: an Egyptian multidisciplinary clinic experience. Surg Endosc. 2014; 28(12): 3429-34. 
34. El-Zayadi AR, Badran HM, Barakat EM, Attia Mel-D, Shawky S, Mohamed MK, et al. Hepatocellular carcinoma in Egypt: A single center study over a decade.World $J$ Gastroenterol. 2005; 11(33): 5193-5198.

35. Lu MD, Xu HX, Xie XY, Yin XY, Chen JW, Kuang M, et al. Percutaneous microwave and radiofrequency ablation for hepatocellular carcinoma :a retrospective comparative study .J Gastroenterol. 2005; 40:1054-1060.

36. Giorgio A, Di Sarno A, De Stefano G, Scognamiglio U, Farella N, Mariniello A, . Percutaneous radiofrequency ablation of hepatocellular carcinoma compared to percutaneous ethanol injection in treatment of cirrhotic patients: an Italian randomized controlled trial. Anticancer Res 2011; 31: 22912295.
37. Zhang L, Wang N, Shen Q, Cheng W, Qian GJ. Therapeutic efficacy of percutaneous radiofrequency ablation versus microwave ablation for hepatocellular carcinoma. PLoS One. 2013 Oct 17; 8(10):e76119.

38. Brunello F, Veltri A, Carucci P, Pagano E, Ciccone G, Moretto P,et al. Radiofrequency ablation versus ethanol injection for early hepatocellular carcinoma: A randomized controlled trial. Scand J Gastroenterol. 2008; 43(6):727-35.

39. Azab M, Zaki S, El-Shetey AG, Abdel-Moty MF, Alnoomani NM, Gomaa AA. Radiofrequency ablation combined with percutaneous ethanol injection in patients with hepatocellular carcinoma. Arab J Gastroenterol. 2011 Sep;12(3):113-8 